\title{
The Time of the Girl
}

\author{
Claudia Mitchell and Jacqueline Reid-Walsh
}

$\cos 80$

The publishing of the articles in this issue of Girlhood Studies coincides with the global events related to the First International Day of the Girl-11 October 2012. This is a day formally declared by the United Nations as the one set aside to articulate the challenges girls face and to promote girls' empowerment and the fulfillment of their human rights. The actual process of gaining official recognition through the United Nations for a specific day is no small feat. The efforts of organizations such as Plan International and even government bodies such as the Status of Women in Canada were key in making this happen in order to address the need for greater understanding of girl-specific issues. In the global context, for example, girls are three times more likely to be malnourished than boys. Of the world's 130 million out-of-school youth, 70 percent are girls. In the Canadian context, as the Minister responsible for the Status of Women highlighted in an International Day of the Girl message, young women from the ages of fifteen to nineteen years experience nearly ten times the rate of date violence as do young men. Close to 70 percent of victims of internet intimidation are women or young girls, and girls and young women are nearly twice as likely as young men and boys to suffer certain mental health problems such as depression, and anxiety about body image and self-esteem remains prevalent among girls. Thus, while October 11 is a time for celebration, it is also a time for reflection and a reminder about how much work there is still to do.

Just how much this entails was very evident in the days surrounding the first International Day of the Girl. Two days earlier, the fourteenyear-old girl activist Malala Yousafzai was shot and critically wounded by the Taliban in Pakistan for her role in taking action to promote girls' education, and on 10 October a Canadian girl, fifteen-year-old Amanda Todd of Coquitlam in the province of British Columbia, 
took her own life as a desperate measure in response to a case of cyberbullying that had its origins several years earlier when she was persuaded by an older man to post a provocative image of herself on the internet. As so many have commented, the events, on the surface, seem very separate and may not appear to have much to do with each other. However, the events caught media attention around the world and as the days and weeks pass, it has become clearer and clearer that they have a great deal to do with each other in relation to the position of girls and the ways in which men in very different societies come to presume ownership in one way or another of them. Both these cases are complex in relation to the lives of girls, and in relation to what they say about girlhood studies more broadly. For example, girls' access to school is clearly about far more than simply resources, with the shooting of Malala Yousafzai an illustrative political act against such access. Amanda Todd's death has signaled new debates about regulation and criminal justice, but has also sparked new questions about victimization and the construction and role of girls' sexuality.

What both incidents also highlight is the need for greater attention to the interactions between and amongst researchers studying girlhood, to the needs of community actors in their providing of programmes for girls, and to informing and supporting policy makers and, of course, to the necessity of involving girls themselves. Based on this, we want to mention a girl-specific event organized to coincide with the International Day of the Girl. This was the conference "Girlhood and the Politics of Space: New Paradigms of Research" which was hosted by the Institute for Gender, Sexuality, and Feminist Studies (IGSFS) of McGill University in Canada, 10-12 October 2012, which brought together researchers, community groups, policy makers and girls to deliberate on critical issues relevant to girls. The symposium participants sought to develop and discuss new analytical tools and conceptual frameworks to study girlhood through cross-disciplinary and cross-national dialogue. We are pleased to report that a future GHS issue will feature a set of the papers from this conference. Another event is the roundtable in Moscow under the auspices of the Gorbachev Foundation: "Girlhood Studies: Prospects and Agenda” on 7 December 2012, which brings together researchers based in Russia and their international counterparts. The importance of exploring girlhood issues in comparative and intersecting ways not only from Montreal to Moscow but around the globe, 
must be kept in mind. Only then is it possible to see how the lives of Malala Yousafzai of Pakistan and Amanda Todd of Canada intersect.

\section{About this issue of Girlhood Studies}

With the publication of this issue in this special time of the girl, Girlhood Studies celebrates its own milestone- the tenth issue of the journal. We have launched approximately 600,000 words on girlhood studies into the world, and close to seventy articles.

The issue begins with Katherine Bell's literary essay, “'A Badly Brought up Member of the Family': Early Adolescence and/as Narrative Rupture in Alice Munro's Lives of Girls and Women." Bell, interested in the emerging academic area of narrative ethics, uses the responses of Alice Munro's protagonist, Del Jordan, an aspiring writer, to consider the ways in which our understanding of the world is shaped by the narrative practices of our family members. Bell focuses on two areas: the first of these is Munro's use of storytelling to foreground the act of narration so as "to heighten the reader's focus on the paradoxical capacity of narrative to fulfill and frustrate desires ... but also sometimes [to] disavow the experiences and feelings of [her]characters." Bell looks at the ways in which Del "exceeds and disrupts the coherent narrativity that the characters in Lives of Girls and Women rely on to situate themselves comfortably in the world." Then she considers the effect on Del of her own excess in an examination of her "coming-of-age experiences that are not easily or readily incorporated into the narratives of others." Bell draws our attention to how the negotiation of one's own narrative in relation to those of others requires consideration of the ethics of narrative in literature and "beyond it."

LuElla D'Amico, in her article, "Possessed by Silence: Cotton Mather, Mercy Short, and the Origin of America's Mean Girls" draws together the ostensibly incompatible-the rousing articulation of response to deeply felt and greatly resented oppressive practices by a Puritan fifteen year-old girl, Mercy Short, and her need to obey the injunctions demanding her silence-in an argument that hinges on the idea that demonic possession enabled her to do both. After all, "[w] hile possessed, it was not [she] who spoke, but the devil.” D’Amico links Mercy's behavior to what has become known as the Mean Girl. As she 
points out, this "good girl versus bad girl paradigm has persisted ... as a staple of ... female identity."

In an analysis of Puritan minister Cotton Mather's 1692 works, Ornaments for the Daughters of Zion - a moral conduct book for girlsand A Brand Pluck'd Out of the Burning - an account of Mercy's demonic possession, D'Amico shows us that Mercy could be Mather's "virtuous maid" while also making sure of her position in Boston society by helping Mather in his determination " to countermine the whole PLOT of the Devil against New-England." We become aware of just how well Mercy "appreciates the complexities of New England's social hierarchies [in] a relational understanding of self [and the world] that girls in contemporary culture continue to exhibit."

In "Boys Fight, Girls Fight": The Social Construction of Girls' Aggression," Melissa K. Levy takes us away from the context of literary texts and into an examination of "young adolescent girls' experience of their and their peers' fighting." As she observes, "[e]xisting research focuses on either boys' violence or girls' non-physical aggression, leaving the realm of girls' physical aggression relatively unexplored." This is Levy's field of interest: how do gender, class and race intersect to affect girls differently from boys. How do girls cope with the "dissonance between anger and femininity" that societal norms create for them in a system that seeks to control aggression and anger in girls but much less so in boys.

Levy understands that the needs of some girls are "served by fighting" and that we need to understand how this is "intertwined with conceptions of race, ethnicity, class, and gender" if we want "to make a positive difference in girls' lives." But, as Levy makes clear, this can begin to happen only if we come to recognize that dominant culture itself, with all its violence, is responsible for manifestations of aggression and that "head-shaking and tongue-clucking at the disgraceful behavior of girls" is not going to accomplish anything at all.

Then Marion Brown takes us back to the notion of the Mean Girl in her article, "Discourses of Choice and Experiences of Constraint: Analyses of Girls' Use of Violence.” In the opening sentence of her abstract Brown points out that " $[\mathrm{g}]$ irls who use violence are marginalized as the worst of the mean girls, disrupting conventional femininity codes and causing panic in the streets." The intersections of analysis here are "neo-liberalism, racism, heterosexism and classism." 
Brown's telling observation that the world in which girls grow up is not the same one that boys inhabit informs her careful analysis. Even though we all know about the violence to which girls are subjected, Brown's description of this sexual harassment, sexism and misogyny as "cultural scripts" stops us up short and makes us recognize that "the internalization of misogyny contributes to a unique context for girls' experience of, and participation in, violence toward girls." What do girls have, Brown asks, apart from the scripts of "neo-liberalism, individualism, heterosexual union, and class compliance" all of which serve to uphold and perpetuate the values and customs of middle-class existence? Seeing violence in girls as deviance and pathology is to ignore these scripts and to minimize the power they have.

In her article, "Miniature Bride or Little Girl Religious: First Communion Clothing in Post-war Spanish Culture and Society, ” Jessamy Harvey's focus is on neither literature nor violence. Her exploration is of the ways in which religious clothing for children demonstrates the "links between the sacred and the market" and how these links have to do not only with consumption but also with issues of identity formation. Harvey's study is of "the historical development of the First Communion, not as religious ritual but as a Catholic consumer culture." She is concerned with the correction of a tendency to make the little girl First Communicant dressed as a bride "the most visible sign" of ideological National Catholicism "because this disregards the cultural practice of wearing clothing to perform piety, signal a vocation or express gratitude for religious intercession." To suggest that Catholic girlhood was monolithic is to disregard its contested nature.

In a fascinating argument Harvey shows us how consumerism connected to the ritual of the First Communion had less to do with nationhood and patriotism than "with popular piety, tradition, and fashion." In making the choice between dressing the girl First Communicant as a bride or in a miniature nun's habit, "her family was dealing with issues of identity, declaring who they were or who they could afford to appear to be, and the adult they wished their daughter to become."

Moving away from dress and into what could be described as a different kind of violence perpetuated against girls and women, Zainul Sajan Virgi addresses in her article, "Poor Quality Health: A Symptom of Gender Inequality for Girls Living with Poverty” the systemic “[a]bject female intergenerational poverty" of young girls in Mozambique. Sajan 
Virgi's research focused on the "lives of a group of ten girls between the ages of ten and fourteen years living in a peri-urban community outside Maputo." Her use of participatory methodologies, "including drawings, photovoice, focus groups, semi-structured qualitative interviews, informal conversations and reflection pieces" served to give these girls an opportunity to talk about their "challenges, strengths and ideas" on how to alleviate the effects of this poverty as well as the poverty itself. Sajan Virgi offers a moving account of the responses of the girls to their constant hunger, their resultant weakened physical state and the inevitable consequence of increased rates of absenteeism from school. We read of the ways in which boys are favored with more and better food and easier access to education. Sajan Virgi points to the fact that until culturally enforced gender inequality is recognized and addressed there is little, if any, hope for these girls.

From these six articles, we go on to include an account of how adolescent girls are using the internet as part of their own reading and critical practices. Allie Shier takes us on a tour of some online book clubs in which e-literate young feminist women respond to texts of mainstream media and popular culture. We learn that the Bitch YA Book Club blog "engages the reader and encourages critical discussion, reflection, and debate about feminist young adult literature." The readergirlz blog on young adult literature seeks to promote teen literacy as well as "the engagement of young females in social service." Its reading group advisory board "showcases strong female protagonists while aiming to include multicultural titles, various socioeconomic circumstances, the overlooked, quiet, literary works, and the commercial successes that everyone is excited about."

Finally, this issue includes three books reviews. In her review of Beatrice Mosionier's (1983) In Search of April Raintree, Jennifer Lahn picks up the threads of violence and identity that run through this issue and weaves them into an account of how two sisters, April and Cheryl Raintree "navigate their way through the Manitoba child welfare system while negotiating their identities and what it means to be Métis." In this mini-essay Lahn shows us that "April is in some ways every child who grows up enduring bullying, racism and erratic treatment in the system and is, thus, representative of the maltreatment that many thousands of children in Canada face every day." She is also every oppressed woman — harassed, stripped of her dignity, and raped—literally 
and then figuratively during the trial of her rapists. The novel, as Lahn notes, addresses these issues "brutally and unapologetically" and illustrates the "devastating effects that these social issues have on individuals, families, entire communities, and races."

In her lively review of Kathleen Sweeney's Maiden USA: Girl Icons Come of Age (2008), Natalie Coulter begins by telling us about Sweeney's "charming ability to toy with language [that] begins with the playful title of the book-Maiden USA: Girl Icons Come of Age-chosen because the goal of her book is to explore, name and analyze the "Icons of the Maiden in American Pop Culture" which are "made in" (4) American popular culture. Similarly, Sweeney plays with the notion that "the Maidens of Pop Culture are Icons but they are also "Eye-cons" — seductive, hypertextual signifiers of girlhood that are continually reproduced within the corporate machinery of popular culture." But Coulter's review is not with criticism: for her the biggest flaw is Sweeney's failure to have the girls themselves interpret the media texts.

Jo Lampert's review of Carolyn Carpan's Sisters, Schoolgirls, and Sleuths: Girls' Series Books in America (2009) brings this issue to its close. For Lampert, this book is excellent as a "genre study, with its reference of book titles, sometimes sentimental biographies and plot summaries" but "far less successful ... as a social history." The real problem here is that Carpan lacks the analytical skills essential to good literary criticism: description and summary replace analysis. "As a compendium to girls' series books, Sisters, Schoolgirls, and Sleuths is commendable ... and ... interesting," says Lampert, but this is not enough.

We acknowledge, most gratefully, Ann Smith's contribution to this editorial. 